\title{
Training driving ability in a traumatic brain-injured individual using a driving simulator: a case report
}

This article was published in the following Dove Press journal:

International Medical Case Reports Journal

10 February 2017

Number of times this article has been viewed

\author{
Sarah Imhoff ${ }^{1,2}$ \\ Martin Lavallière ${ }^{3,4}$ \\ Mathieu Germain- \\ Robitaille ${ }^{5}$ \\ Normand Teasdale $\mathrm{e}^{5-7}$ \\ Philippe Fait ${ }^{1,2,8}$ \\ 'Department of Human \\ Kinetics, ${ }^{2}$ Research Group on \\ Neuromusculoskeletal Dysfunctions \\ (GRAN), Université du Québec à \\ Trois-Rivières, Trois-Rivières, QC, \\ Canada; ${ }^{3}$ Massachusetts Institute of \\ Technology AgeLab, Cambridge, MA, \\ USA; ${ }^{4}$ Department of Health Sciences, \\ Program of Kinesiology, Université \\ du Québec à Chicoutimi, Chicoutimi, \\ ${ }^{5}$ Faculté de Médecine, Département \\ de Kinésiologie, ${ }^{6} \mathrm{Groupe}$ de \\ recherche en analyse du mouvement \\ et ergonomie, Université Laval, ${ }^{7} \mathrm{CHU}$ \\ de Québec - Université Laval, Centre \\ d'excellence sur le vieillissement \\ de Québec, ${ }^{8}$ Research Center in \\ Neuropsychology and Cognition \\ (CERNEC), Montréal, QC, Canada
}

Correspondence: Philippe Fait Université du Québec à Trois-Rivières, 335I Boulevard des Forges, C.P. 500, Trois-Rivières, QC, G9A 5H7, Canada Tel +I 819376501 lext3768

Fax +I 8193765092

Email philippe.fait@uqtr.ca
Background: Traumatic brain injury (TBI) causes functional deficits that may significantly interfere with numerous activities of daily living such as driving. We report the case of a 20 -yearold woman having lost her driver's license after sustaining a moderate TBI.

Objective: We aimed to evaluate the effectiveness of an in-simulator training program with automated feedback on driving performance in a TBI individual.

Methods: The participant underwent an initial and a final in-simulator driving assessment and 11 in-simulator training sessions with driving-specific automated feedbacks. Driving performance (simulation duration, speed regulation and lateral positioning) was measured in the driving simulator.

Results: Speeding duration decreased during training sessions from $1.50 \pm 0.80 \mathrm{~min}$ (4.16 $\pm 2.22 \%)$ to $0.45 \pm 0.15 \mathrm{~min}(0.44 \pm 0.42 \%)$ but returned to initial duration after removal of feedbacks for the final assessment. Proper lateral positioning improved with training and was maintained at the final assessment. Time spent in an incorrect lateral position decreased from $18.85 \mathrm{~min}(53.61 \%)$ in the initial assessment to $1.51 \mathrm{~min}(4.64 \%)$ on the final assessment.

Conclusion: Driving simulators represent an interesting therapeutic avenue. Considerable research efforts are needed to confirm the effectiveness of this method for driving rehabilitation of individuals who have sustained a TBI.

Keywords: traumatic brain injury, rehabilitation, driving, simulator, assessment

\section{Introduction}

Traumatic brain injury (TBI) causes functional deficits that may significantly interfere with numerous activities of daily living (ADL) such as driving, ${ }^{1-4}$ which is a strong symbol of autonomy. ${ }^{5,6}$ Since driving requires operational (basic driving skills such as lateral positioning and speed control), tactical (judgment and anticipation) and strategic level of control (route planning), ${ }^{2,7,8}$ resuming driving following TBI may be challenging. Thus, only $40 \%-60 \%$ of moderate-to-severe TBI individuals return to driving. ${ }^{3,6,9-15}$

\section{Case report}

We report the case of a 20-year-old woman who lost her driver's license after sustaining a moderate TBI in May 2013 after a car crash involving a deer. When transferred to intensive care, she presented a score of 10/15 on the Glasgow Coma Scale (GCS). ${ }^{16}$ Following the accident, she presented a posttraumatic amnesia, diffuse axonal injury with several bilateral petechiae, hemorrhagic contusions mostly located in the right frontal lobe, an infringement of the third right cranial nerve, mild right optic neuropathy, left hemiparesis, balance impairment (43/56 on Berg Balance Scale (BBS), ${ }^{17}$ 
difficulty in performing ADL and cognitive impairments, including memory impairment, decline in audioverbal and visual attention, decline in the ability of abstraction, reduced organizational capacity, decreased visuospatial abilities, cognitive fatigability and apathy.

At the time of the accident, the participant held a Learner's License - Passenger Vehicle (Class 5) and had very little driving experience. Having failed her first attempt to the Probationary License - Passenger Vehicle (Class 5), she was planning to perform her second attempt to the Société de l'Assurance Automobile du Québec (SAAQ) on-road test as required by Quebec's provincial legislation.

In order to regain her Learner's License - Passenger Vehicle (Class 5), she had to obtain an evaluation certifying her functional capacity for driving. She underwent an in-clinic assessment, which revealed mild posttraumatic cognitive impairments (i.e., cognitive fatigability that interferes with the sustained attention span and vigilance weakness that generates a slow reaction time when stimuli appear slowly); sufficient muscle strength, range of motion and coordination; proper reaction time; sufficient overall perceptual-cognitive functions for driving and sufficient behavior. Following this assessment, she received a 10-hour on-road driving training with a driving instructor and a 3-hour in-simulator-specific road rules learning with a driving instructor. Driving ability of the posttrauma subject was assessed during an on-road evaluation conducted by an occupational therapist in May 2014 at the Quebec City Rehabilitation Institute (IRDPQ). During this test, the participant did not demonstrate the operational and tactical skills required to drive safely. The difficulties observed during the road test were consistent with cognitive sequelae observed in clinical settings. These seemed to cause functional impairments interfering with her driving performance. Considering the deficiencies observed during the on-road assessment, the lack of improvement during training sessions and the integration difficulties of the basics of driving, the improvement potential was estimated as low. Therefore, no other subsequent road test was envisaged by the IRDPQ.

In-simulator driving rehabilitation presents a promising method to improve driving skills after TBI. ${ }^{18,19}$ The aim of this study is to evaluate the effectiveness of an in-simulator training program with automated feedback on driving performance in a TBI individual.

\section{Methods}

\section{Procedure}

A 20-year-old woman was recruited at the Quebec City Rehabilitation Institute (IRDPQ) after failing the on-road evaluation assessing her fitness to drive in order to earn back her driving license. The participant provided written informed consent to have this case report published. The participant underwent 11 in-simulator training sessions (over a 5-week period) with driving-specific automated feedbacks on the driving performance issued during the simulation. An initial and a final in-simulator driving assessment was performed before and after the in-simulator driving rehabilitation training. Feedbacks were not audible during these two simulation-based evaluations. In order to avoid simulator sickness, a $15 \mathrm{~min}(6 \mathrm{~km})$ in-simulator straight long course was conducted before all simulation sessions. The driving training and assessment scenario $(27.5 \mathrm{~km})$ included $19.6 \mathrm{~km}$ of rural and $7.9 \mathrm{~km}$ of urban sections. She was asked to follow Québec's Highway safety code (R.S.Q, Chapter c-24.2). The course included similar operations to those carried out on the road such as managing lane change, intersection stop signs, traffic lights, turns and overtaking. The same course was used across all sessions. The scenario events were carefully planned to unravel in exactly the same way for any driving speed.

Automated auditory driving-specific feedbacks were issued during the simulation according to the following criteria: 1) exceeding a speed of $10 \mathrm{~km} / \mathrm{h}$ above the speed limit and 2) maintaining lateral vehicle position of $>15 \%$ of the lane width to the left or the right of the center of the lane (i.e., tires $<15 \mathrm{~cm}$ from the nearest line) for $>5 \mathrm{~s}$. Additional warnings were sent every $10 \mathrm{~s}$ until the vehicle speed or lateral position decreased under these thresholds.

\section{Material}

Driving simulation was conducted on a fixed-based open-cab simulator that consists of an instrumented sedan (brake and accelerator pedals, steering and automatic transmission). STISIM Drive 3.0 (System Technology Inc., Hawthorne, CA, USA) software displayed image of the driving scene on a $1.2 \mathrm{~m}$ high by $1.6 \mathrm{~m}$ wide flat screen using a projector Hitachi CPX8, which provides a $40^{\circ}$ horizontal by $30^{\circ}$ vertical field of view and recorded the driver's performance. Auditory driving stimuli and automated feedbacks were displayed through a piezoelectric speaker (100 ms, $1.5 \mathrm{kHz})$.

\section{Data analysis}

Considering the single-case nature of the data collection, descriptive statistics about duration of the simulation, speed regulation and lateral positioning are presented. Data analysis was conducted on the initial and final assessment sessions and on training sessions 1-3 and 9-11. Mean and standard deviation are presented. These sessions were selected to analyze the effects of training and need for feedbacks on driving 
performance. Basic simulator data of speed and vehicle lateral position were used to evaluate driving performance. ${ }^{20,21}$ Exceeding a speed of $10 \mathrm{~km} / \mathrm{h}$ above and below the speed limit was considered as a speed regulation error. Lateral positioning error was defined by maintaining lateral vehicle position of $>15 \%$ of the lane width to the left or the right of the center of the lane (i.e., tires $<15 \mathrm{~cm}$ from the nearest line).

\section{Results}

Initial assessment was completed in $35.15 \mathrm{~min}$. On average, the time to complete the scenario was stable in the first three $(36.00 \pm 0.44 \mathrm{~min})$ and last three $(37.33 \pm 0.64 \mathrm{~min})$ in-simulator trainings. The participant completed the final assessment in $32.63 \mathrm{~min}$.

The participant drove $1.26 \mathrm{~min}$ (3.58\%) over the speed limit $(>10 \mathrm{~km} / \mathrm{h})$ during initial assessment. This time decreased during training sessions from $1.50 \pm 0.80 \mathrm{~min}$ $(4.17 \% \pm 2.23 \%)$ to $0.45 \pm 0.15 \min (1.20 \% \pm 0.42 \%)$. Upon removal of feedbacks for the final assessment, speeding went back to the initial duration (1.31 min, $4.00 \%)$. Even if no feedbacks regarding speed below speed limit were issued during training, we measured the time during which the participant was driving $<10 \mathrm{~km} / \mathrm{h}$ below speed limit. After removing mandatory stops and red light intersections, time spent driving $10 \mathrm{~km} / \mathrm{h}$ slower than the speed limit initially totaled $10.56 \mathrm{~min}(30.04 \%)$, increased to $13.92 \pm 2.39 \mathrm{~min}$ $(38.63 \% \pm 6.15 \%)$ for the three first training sessions with feedback to and was relatively stable at $15.95 \pm 2.59 \mathrm{~min}$ $(42.65 \pm 6.26 \%)$ on sessions $9-11$. Time spent driving at a speed of $10 \mathrm{~km} / \mathrm{h}$ slower than the speed limit decreased greatly during the final evaluation (6.18 $\mathrm{min}, 18.94 \%$ ). Speed regulation results are presented in Figure 1.
The maintenance of the vehicle lateral position further apart than $15 \%$ of the lane width to the left or the right of the center of the lane was considered as a driving error. She spent $18.85 \mathrm{~min}(53.61 \%)$ in an incorrect lateral position at the initial assessment. With feedbacks, time spent in an improper lane positioning decreased rapidly and was maintained over time for training sessions $1-3(5.83 \pm 1.84 \mathrm{~min}$, $16.23 \pm 5.25 \%), 9-11(2.37 \pm 0.66 \mathrm{~min}, 6.34 \pm 1.70 \%)$ and on the final assessment without feedback (1.51 min, 4.64\%). These results are presented in Figure 2.

\section{Discussion}

The objective was to report the driving adaptations following an in-simulator driving rehabilitation training program with

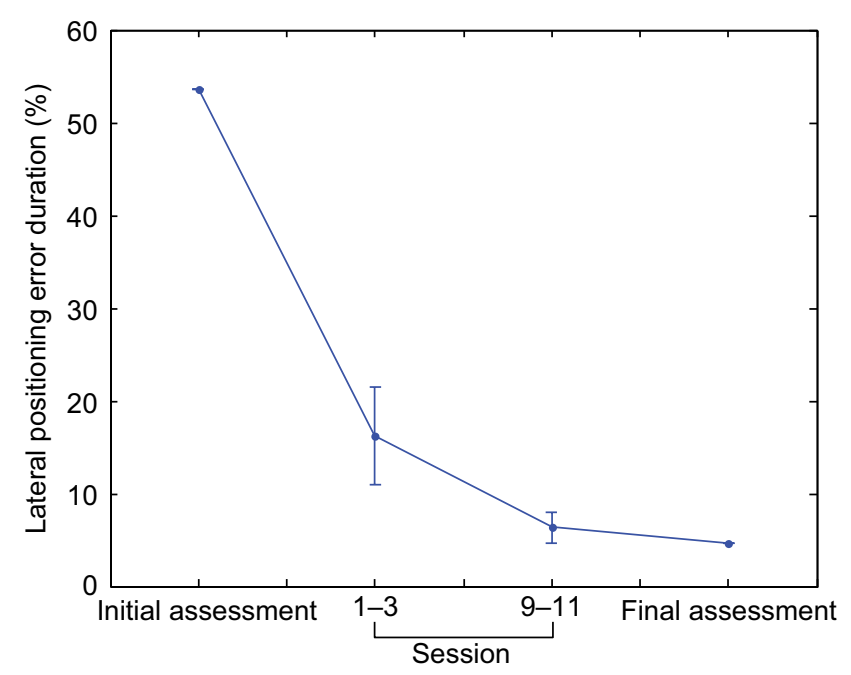

Figure 2 Proportion of positioning errors duration.

Note: Proportion of the positioning error duration relative to the simulation duration (\%) presented by the number of sessions.
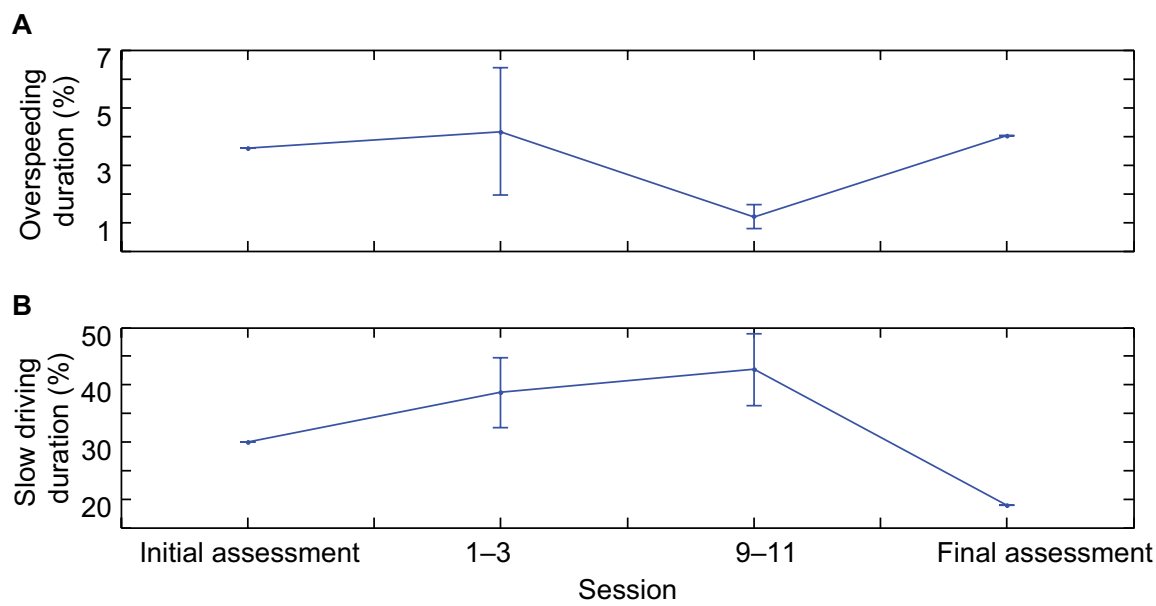

Figure I Speed regulation results.

Notes: Proportion of over speeding duration relative to the simulation duration (\%) presented by the number of sessions (A). Proportion of slow driving relative to the simulation duration (\%) presented by the number of sessions (B). 
automated feedback on driving performance in TBI individual. Improvement in speed regulation and lateral positioning was observed through the in-simulator training sessions.

The participant responded to specific auditory feedbacks while training by reducing speeding error duration. However, this adaptation was not maintained after removing the feedbacks. In general, the participant was driving too slowly during training. Interestingly, time to complete the scenario was shorter on final assessment, which represents a higher overall speed without impacts on speeding duration. This might have indicated that participant was more attentive to speed regulation after the in-simulator training program. We have to consider that the participant aimed to regain her driving license. Therefore, she had to obtain an evaluation certifying her functional capacity for driving. Before the in-simulator final assessment, the participant had access to an on-road learning session through the IRDPQ driving rehabilitation program during which the driving instructor told her that she was driving too slowly. This may impact her driving behavior and may explain higher overall speed on final simulator assessment. Lateral positioning improved greatly with training and maintained after feedback removal. This indicated that the introduction of real-time feedback emission impacted this specific driving behavior.

To our knowledge, only two other studies aimed to rehabilitate fitness to drive in TBI drivers using in-simulator training program. Our results are consistent with those of Cox et $\mathrm{al}^{18}$ and Gamache et al, ${ }^{19}$ which demonstrated improvements in in-simulator driving skills such as lateral positioning, speed regulation, steering through turns and brake control following an in-simulator rehabilitation training. This case study shows that automated auditory driving-specific feedbacks may be beneficial when issued while relearning to drive in a simulator. However, participant's dependence on feedbacks and transfer of driving improvements to on-road driving task remain unclear. There is anecdotal evidence that this method can be successful as the patient in the study by Gamache et $\mathrm{al}^{19}$ succeeded in regaining her driving license. ${ }^{22}$

At the end of the present study, the patient's functional capacity for driving was assessed by an on-road driving evaluation conducted by an occupational therapist. ${ }^{23}$ The occupational therapist concluded that, in comparison with the previous on-road test conducted earlier, the participant presented improved operational skills. Although some tactical skills improvements were observed, anticipation, situation analysis, planning, attention and vigilance were not compatible with safety requirements for driving. The participant demonstrated appropriate operational skills (basic driving skills as lateral positioning and speed control) but not tactical skills (judgment and anticipation). Therefore, her Learner's License - Passenger Vehicle (Class 5) was not renewed. Several studies demonstrated that novice drivers show a wide range of driving deficits when compared to experience drivers. ${ }^{24-37}$ Moreover, novice drivers may successfully develop basic operational driving skills through training without developing the tactical and strategic skills required for safe driving. ${ }^{24,28,37}$ Therefore, although deficits observed during the on-road assessment have been attributed to posttraumatic sequelae, contribution of the participant's driving experience in driving prior to TBI should be considered. Further, our in-simulator-specific feedbacks focused on operational skills through a unique training scenario with limited range of challenging situations. This could limit the transfer to improvement in tactical skills.

\section{Conclusion}

This pilot study shows that a TBI individual responded positively to feedback during an in-simulator driving rehabilitation training program and that some of the improvements in driving performance were maintained after the instantaneous feedback was removed. Since TBI causes functional deficits that may affect the ability to drive, it is imperative to develop effective rehabilitation method. In-simulator driving rehabilitation training may represent an interesting therapeutic avenue. Although an insufficient number of studies have investigated the potential of driving rehabilitation, considerable research efforts are needed to confirm the effectiveness of this method in driving rehabilitation of TBI individuals.

\section{Acknowledgments}

Sarah Imhoff was supported by a research grant - Recherche en sécurité routière: Fonds de recherche du Québec-Société et culture (FRQSC), Société de l'assurance automobile du Québec (SAAQ), Fonds de recherche du Québec - Santé (FRQS). Martin Lavallière was supported by a postdoctoral research grant - Recherche en sécurité routière: Fonds de recherche du Québec - Société et culture (FRQSC), Société de l'assurance automobile du Québec (SAAQ), Fonds de recherche du Québec - Santé (FRQS).

\section{Disclosure}

The authors report no conflicts of interest in this work.

\section{References}

1. Canadian Institute for Health Information. Head injuries in Canada: $A$ Decade of Change (1994-1995 to 2003-2004). Toronto, ON: Canadian Institute for Health Information; 2006.

2. Bottari C, Lamothe MP, Gosselin N, Gélinas I, Ptito A. Driving difficulties and adaptive strategies: the perception of individuals having sustained a mild traumatic brain injury. Rehabil Res Pract. 2012;837301(10):13. 
3. Canadian Council of Motor Transport Administrators. Determining Driver Fitness in Canada: Part 1: Administration of Driver Fitness Programs and Part 2: CCMTA Medical Standards for Drivers CCMTA Reports. 13th ed. Ottawa: CCMTA; 2013:1-317.

4. Ponsford JL, Downing MG, Olver J, et al. Longitudinal follow-up of patients with traumatic brain injury: outcome at two, five, and ten years post-injury. J Neurotrauma. 2014;31(1):64-77.

5. Berger JT, Rosner F, Kark P, Bennett AJ. Reporting by physicians of impaired drivers and potentially impaired drivers. The Committee on Bioethical Issues of the Medical Society of the State of New York. J Gen Intern Med. 2000;15(9):667-672.

6. Rapport LJ, Bryer RC, Hanks RA. Driving and community integration after traumatic brain injury. Arch Phys Med Rehabil. 2008;89(5): 922-930.

7. Lundqvist A, Alinder J. Driving after brain injury: self-awareness and coping at the tactical level of control. Brain Inj. 2007;21(11):1109-1117.

8. Michon JA. Explanatory pitfalls and rule-based driver models. Accid Anal Prev. 1989;21(4):341-353.

9. Novack TA, Labbe D, Grote M, et al. Return to driving within 5 years of moderate-severe traumatic brain injury. Brain Inj. 2010;24(3):464-471.

10. Coleman RD, Rapport LJ, Ergh TC, Hanks RA, Ricker JH, Millis SR. Predictors of driving outcome after traumatic brain injury. Arch Phys Med Rehabil. 2002;83(10):1415-1422.

11. Fisk GD, Schneider JJ, Novack TA. Driving following traumatic brain injury: prevalence, exposure, advice and evaluations. Brain Inj. 1998;12(8):683-695.

12. Nalder E, Fleming J, Cornwell P, et al. Recording sentinel events in the life course of individuals with acquired brain injury: a preliminary study. Brain Inj. 2012;26(11):1381-1396.

13. Leon-Carrion J, Dominguez-Morales MR, Martin JM. Driving with cognitive deficits: neurorehabilitation and legal measures are needed for driving again after severe traumatic brain injury. Brain Inj. 2005;19(3): 213-219.

14. Bivona U, D'Ippolito M, Giustini M, et al. Return to driving after severe traumatic brain injury: increased risk of traffic accidents and personal responsibility. J Head Trauma Rehabil. 2012;27(3):210-215.

15. Bazarian JJ, Wong T, Harris M, Leahey N, Mookerjee S, Dombovy M. Epidemiology and predictors of post-concussive syndrome after minor head injury in an emergency population. Brain Inj. 1999;13(3):173-189.

16. Teasdale G, Jennett B. Assessment of coma and impaired consciousness. A practical scale. Lancet. 1974;2(7872):81-84.

17. Berg KO, Wood-Dauphinee SL, Williams JI, Maki B. Measuring balance in the elderly: validation of an instrument. Can J Public Health. 1992;83(suppl 2):S7-S11.

18. Cox DJ, Davis M, Singh H, et al. Driving rehabilitation for military personnel recovering from traumatic brain injury using virtual reality driving simulation: a feasibility study. Mil Med. 2010;175(6):411-416.

19. Gamache PL, Lavalliere M, Tremblay M, Simoneau M, Teasdale N. In-simulator training of driving abilities in a person with a traumatic brain injury. Brain Inj. 2011;25:416-425.

20. Classen S, Brooks J; National Highway Traffic Safety Administration; American Occupational Therapy Association. Driving simulators for occupational therapy screening, assessment, and intervention. Occup Ther Health Care. 2014;28(2):154-162.
21. Hoffman L, McDowd JM. Simulator driving performance predicts accident reports five years later. Psychol Aging. 2010;25(3):741-745.

22. Lavallière M, editor. Entraînement sur simulateur chez une personne ayant subi un traumatisme crânien sévère et transfert des apprentissages sur la route. Abstract presented at: 23rd Canadian Multidisciplinary Road Safety Conference, May 26-29; 2013; Montréal, QC, Canada. Available from: www.cmrsc.polymtl.ca/Abstracts/8A/104.pdf. Accessed February 02,2017

23. Michon JA. A critical view of driver behavior models. In: Evans L, Schwing RC, editors. Human Bahavior and Traffic Safety. New York, NY: Plenum Press; 1985:485-520.

24. Durbin DR, Mirman JH, Curry AE, et al. Driving errors of learner teens: frequency, nature and their association with practice. Accid Anal Prev. 2014;72:433-439.

25. Chan E, Pradhan AK, Pollatsek A, Knodler MA, Fisher DL. Are driving simulators effective tools for evaluating novice drivers' hazard anticipation, speed management, and attention maintenance skills. Transp Res Part F Traffic Psychol Behav. 2010;13(5):343-353.

26. Fisher DL, Laurie NE, Glaser R, et al. Use of a fixed-base driving simulator to evaluate the effects of experience and PC-based risk awareness training on drivers' decisions. Hum Factors. 2002;44(2):287-302.

27. Laapotti S, Keskinen E, Hatakka M, Katila A. Novice drivers' accidents and violations - a failure on higher or lower hierarchical levels of driving behaviour. Accid Anal Prev. 2001;33(6):759-769.

28. Lehtonen E, Lappi O, Koirikivi I, Summala H. Effect of driving experience on anticipatory look-ahead fixations in real curve driving. Accid Anal Prev. 2014;70:195-208.

29. Parmet Y, Borowsky A, Yona O, Oron-Gilad T. Driving speed of young novice and experienced drivers in simulated hazard anticipation scenes. Hum Factors. 2015;57(2):311-328.

30. Underwood G. On-road behaviour of younger and older novices during the first six months of driving. Accid Anal Prev. 2013;58:235-243.

31. Borowsky A, Oron-Gilad T. Exploring the effects of driving experience on hazard awareness and risk perception via real-time hazard identification, hazard classification, and rating tasks. Accid Anal Prev. 2013;59:548-565.

32. Ross V, Jongen EM, Wang W, et al. Investigating the influence of working memory capacity when driving behavior is combined with cognitive load: an LCT study of young novice drivers. Accid Anal Prev. 2014; $62: 377-387$

33. Scott H, Hall L, Litchfield D, Westwood D. Visual information search in simulated junction negotiation: gaze transitions of young novice, young experienced and older experienced drivers. J Safety Res. 2013;45: 111-116.

34. Scialfa CT, Borkenhagen D, Lyon J, Deschênes M, Horswill M, Wetton M. The effects of driving experience on responses to a static hazard perception test. Accid Anal Prev. 2012;45:547-553.

35. McKnight AJ, McKnight AS. Young novice drivers: careless or clueless? Accid Anal Prev. 2003;35(6):921-925.

36. Chapman PR, Underwood G. Visual search of driving situations: danger and experience. Perception. 1998;27(8):951-964.

37. Groeger JA, Banks AP. Anticipating the content and circumstances of skill transfer: unrealistic expectations of driver training and graduated licensing? Ergonomics. 2007;50(8):1250-1263.
International Medical Case Reports Journal

\section{Publish your work in this journal}

The International Medical Case Reports Journal is an international peer-reviewed open-access journal publishing original case reports from all medical specialties. Previously unpublished medical posters are also accepted relating to any area of clinical or preclinical science. Submissions should not normally exceed 2,000 words or
4 published pages including figures, diagrams and references. The manuscript management system is completely online and includes a very quick and fair peer-review system, which is all easy to use. Visit http://www.dovepress.com/testimonials.php to read real quotes from published authors. 